lización. Por una parte se han escuchado experiencias sobre proyectos que sobrepasan los límites clásicos, de manera que en ellos se combina lo que podemos conocer como patrimonio cultural al uso, con espacios naturales o itinerarios culturales, en los que la complejidad de matices se une a la riqueza de resultados tal y como sucede en los Sacro Montes italianos o en algún proyecto inglés como el relacionado con la Muralla de Adria- no. En este sentido no podemos olvidar la trascendencia de la presentación de esos recursos, la importancia de los montajes y de algún modo la manipulación objetual o espacial, para dar lugar a una interpretación concreta. Sin duda todas las sugerencias en este campo son buenas y fomentan la creatividad y la renovación de los usos al servicio de una exposición más atractiva.
De este modo se han abordado temas diversos con soluciones distintas; ideas novedosas y caminos alternativos en un campo, el del Patrimonio Cultural, intrínsecamente unido a nuestra memoria y del que todos somos responsables directos.

Fundación del Patrimonio Histórico de Castilla y León

\title{
Encuentro de especialistas sobre Inventarios y Cartas Arqueológicas aplicados al Patrimonio Arqueológico Subacuático
}

Entre los días 22 y 24 de octubre se han desarrollado en la ciudad de Santiago de Chile las II Jornadas Latinoamericanas de Arqueología Subacuática, encuentro organizado por la Universidad Internacional SEK, en el marco del Programa de Arqueología Subacuática implementado por el Área de Arqueología de su Facultad de Estudios del Patrimonio Cultural !.

El encuentro, que ha contado con la presencia de destacados investigadores de diferentes instituciones científicas y nacionalidades (Argentina, Brasil, Chile, España, México, Noruega y Uruguay), ha sido importante por cuanto ha supuesto, en una primera instancia, un paso más hacia la consolidación de una línea de investigación con poco tiempo de desarrollo en Chile y que fue introducida por la Universidad Internacional SEK motivada por la falta de información generalizada en la sociedad chilena -y en el sector académico en particular-sobre el manejo del patrimonio histórico subacuático, propiciada en gran medida por el escaso desarrollo de proyectos de intervención en cualquiera de sus modalidades (prospección, excavación, conservación, restauración), y puesta de manifiesto en la inexistencia de equipos de investigación que ejecutasen líneas de acción en estas áreas, así como la ausencia de éstas en los planes de estudio de las carreras universitarias actuales. Este vacío se acusa aún más cuando, como consecuencia de esta situación, los restos que yacen en el medio acuático no son considerados como elementos patrimoniales y por ello son presas fáciles del expolio.

Ante esta situación común prácticamente para todos los países latinoamericanos, parecía aconsejable apoyar acciones conducentes a proporcionar un mayor conocimiento de

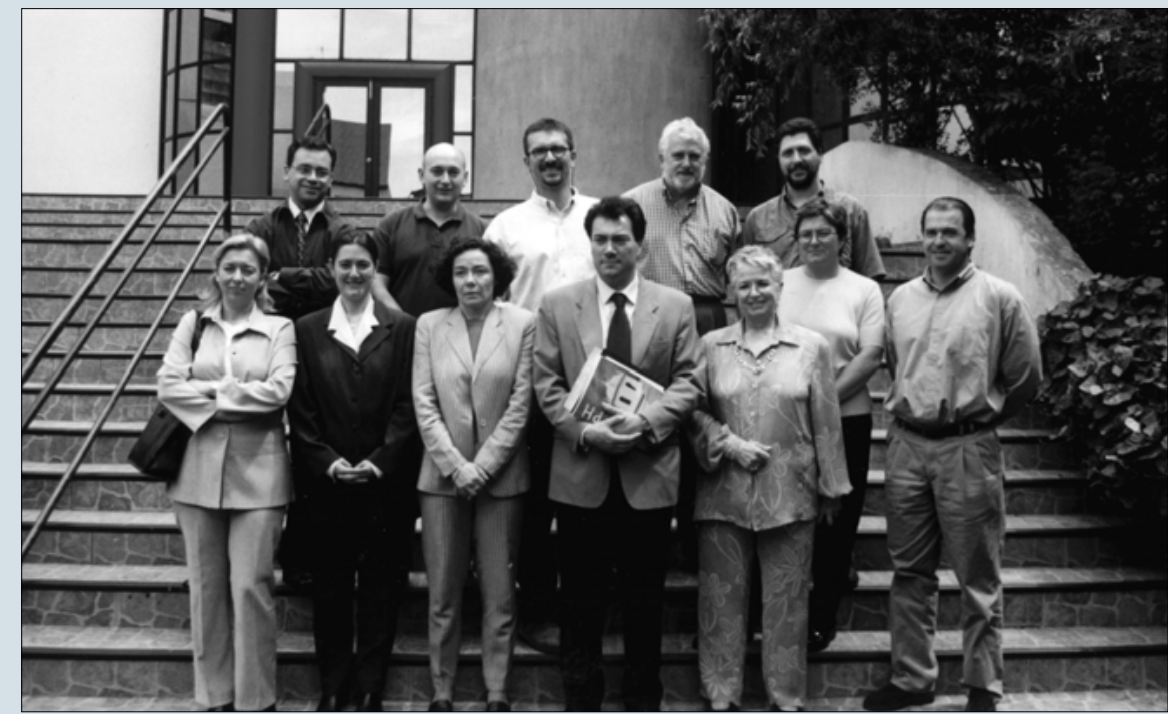

esta realidad tal que permitiera adquirir un mayor grado de sensibilidad frente a una parte del patrimonio casi olvidada. En este sentido, las acciones encaminadas a la difusión deberían concebirse como prioritarias, toda vez que su ejercicio permite el intercambio de experiencias de las que emanen modelos concretos de aplicación.

De igual forma, y en una segunda instancia, ha sido importante porque su desarrollo ha permitido dar continuidad a las Jornadas que tuvieron su primera versión en el año 1997. En aquella ocasión se reunieron especialistas de Argentina, Colombia, Cuba, Chile, España, México y República Dominicana, con el fin de que se expusiera el grado de avance experimentado por estos países en los ámbitos de Gestión, Investigación y Conservación y Difusión del Patrimonio Cultural Subacuático, los que se erigieron en la temática central de aquel en- cuentro. De su desarrollo se pudo constatar dos aspectos fundamentales: en primer lugar, diferencias en el desarrollo de proyectos de investigación del patrimonio sumergido entre los distintos países latinoamericanos -mientras se pudo constatar una mayor trayectoria en el contexto caribeño, el resto de países sudamericanos se caracterizaron por una incipiente actividad investigadora y la carencia de especialistas que la desarrollen-; en segundo lugar, diferencias también en los mecanismos implementados para la gestión del patrimonio sumergido, siendo lo más destacable la disparidad de normativas vigentes -conviven países que poseen legislaciones proteccionistas con países en los que la consideración del patrimonio cultural subacuático constituye un verdadero vacío legal-; y la falta de un respaldo financiero estatal necesario para impulsar el estudio y protección del patrimonio sumergido. 


\section{Noticias y Comentarios}

La temática central de la reunión de este año ha sido la de Inventarios y Cartas Arqueológicas, inspirada en uno de los siete acuerdos establecidos por los componentes de las mesas de trabajo de la primera reunión y que recogemos a continuación:

"Entendemos por gestión del Patrimonio Cultural Subacuático el conjunto de acciones conducentes a su conocimiento, su conservación y su difusión.

El conocimiento exhaustivo del patrimonio sumergido permite aplicar estrategias de protección sobre el mismo. Por ello, el desarrollo de inventarios y cartas arqueológicas, permite conocer el potencial arqueológico de un país, por lo que el diseño y ejecución de estas herramientas deben ser una prioridad en la gestión del Patrimonio Cultural Subacuático de cada nación. A este respecto, se propone trabajar para la creación de una base de datos común de ámbito latinoamericano." 2

Así pues, siendo consecuentes con este punto, estas II Jornadas han vuelto a reunir en Santiago a II investigadores que desde sus respectivas instituciones han desarrollado o están desarrollando inventarios y cartas arqueológicas en sus países de origen, a fin de que sus experiencias sirvan de punto de par- tida y marco a la Carta que la Universidad Internacional SEK se ha propuesto crear para todo el contexto nacional bajo el Proyecto SICAS (Sistema de Información Cartográfico de Arqueología Subacuática). De esta forma, las distintas exposiciones han versado sobre distintos aspectos atingentes a la temática central del encuentro: prospección, sistemas de registro, modelos de organización de la información, empleo de bases de datos cartográficas y alfanuméricas, entre otros aspectos, con enfoques teóricos, metodológicos y prácticos.

Además, las mesas de trabajo se centraron en el desarrollo del marco legal que permita el registro y puesta en marcha oficial de la Asociación Latinoamericana de Arqueología Subacuática, propuesta que se gestó durante el desarrollo del las Jornadas del '97 y que se concibe como una corporación sin ánimo de lucro en torno a la cual se congreguen especialistas e interesados de distintas nacionalidades que, a título personal o institucional, aúnen esfuerzos en contribuir a la preservación del patrimonio cultural subacuático latinoamericano. Con sede en el Campus Parque Arrieta de la Universidad Internacional SEK, su función será, principalmente, la de impulsar acciones en pro del cumplimiento de este fin y velar por el mantenimiento de estos encuentros con una periodicidad de dos años ${ }^{3}$ como forma de actualización de conocimientos e intercambios de experiencias que tiendan a solucionar los múltiples problemas que caracterizan al desarrollo de esta modalidad de la ciencia arqueológica en el subcontinente americano.

\section{Pedro Pujante Izquierdo}

Coordinador de las Jornadas Universidad Internacional SEK

\section{Notas}

I. Las II Jornadas Latinoamericanas de Arqueología Subacuática han contado con el patrocinio de ICOMOSChile y la Corporación del Patrimonio Cultural de Chile, así como con el auspicio del Centro Cultural de España (Agencia Española de Cooperación Internacional), Hotel Carrera, LOM Ediciones y Nescafé.

2. Pujante Izquierdo, P. (Ed.): Gestión, Investigación y Conservación y Difusión del Patrimonio Cultural Subacuático. Actas de las I Jornadas Latinoamericanas de Arqueología Subacuática. Santiago de Chile, 25 al 28 de noviembre de 1997. Santiago de Chile: Ediciones de la Universidad Internacional SEK - Fundación Andes, 200I, p. 8.

3. Siguiendo este principio ya establecido en 1997, los miembros que constituyeron las mesas de trabajo acordaron realizar las siguientes Jornadas en el 2003 en República Dominicana.

\section{El turista cultural tiene un nivel de gastos superior que el visitante de sol y playa}

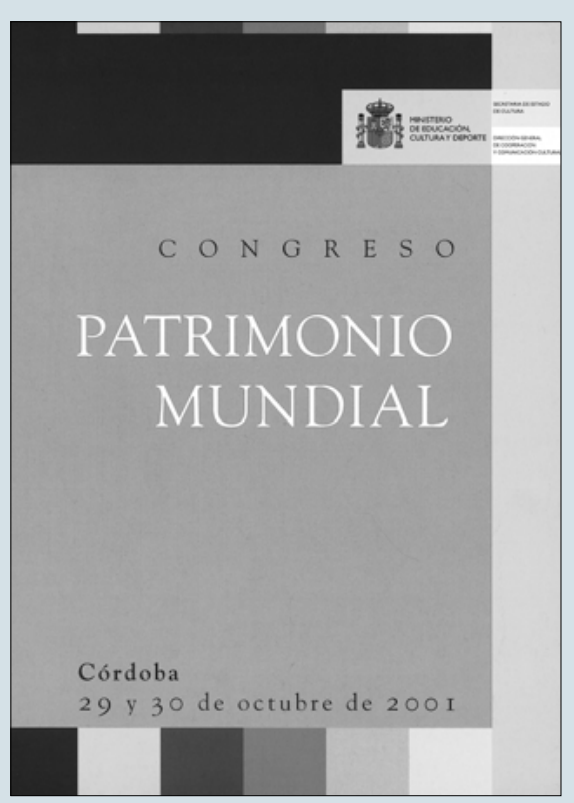

Córdoba acogió entre los días 29 y 30 de octubre el Congreso de Patrimonio Mundial, organizado por la Dirección General de Cooperación y Comunicación Cultural del Ministerio de Educación, Cultura y Deporte. En el acto inaugural, presidido por la Ministra de Educación, Cultura y Deporte, Pilar del Castillo, José Luis Álvarez Álvarez afirmó que el patrimonio mundial general unos efectos económicos extraordinarios, ya que se registran unos $697 \mathrm{mi}-$ llones de turistas al año en el mundo. En España ingresos en torno a los 6.500 millones de pesetas al año, generados por los 48 millones de turistas que se reciben. Según el académico de las Bellas Artes de San Fernando, el turista cultural tiene un nivel de gastos superior que el visitante de sol y playa. También señalo que estos datos deben repercutir en la defensa del patrimonio y que justifican la inversión en conservación de ese patrimonio y en educación destinada a valorarlo.
Los objetivos de este Congreso pueden concretarse en los siguientes puntos:

I. Profundizar en la difusión de la importancia del patrimonio del cual es usufructuaria la Humanidad entera.

2. Continuar en la línea que se inició en el Congreso Internacional de Itinerarios Culturales, celebrado en Santiago de Compostela (2000), de propiciar iniciativas que, uniendo turismo y cultura, se conviertan en un medio ideal para acercar a los ciudadanos al disfrute de nuestro patrimonio histórico.

3. Propiciar la comunicación entre instituciones públicas (Ministerio de Educación, Cultura y Deporte, Instituto Andaluz de Patrimonio Histórico, Real Academia de Bellas Artes de San Fernando, Universidad de Barcelona, Unesco, etc), de instituciones privadas de ca- 